ANO $10 \bullet$ NÚMERO $18 \bullet 2013 \bullet$ ORGANICOM
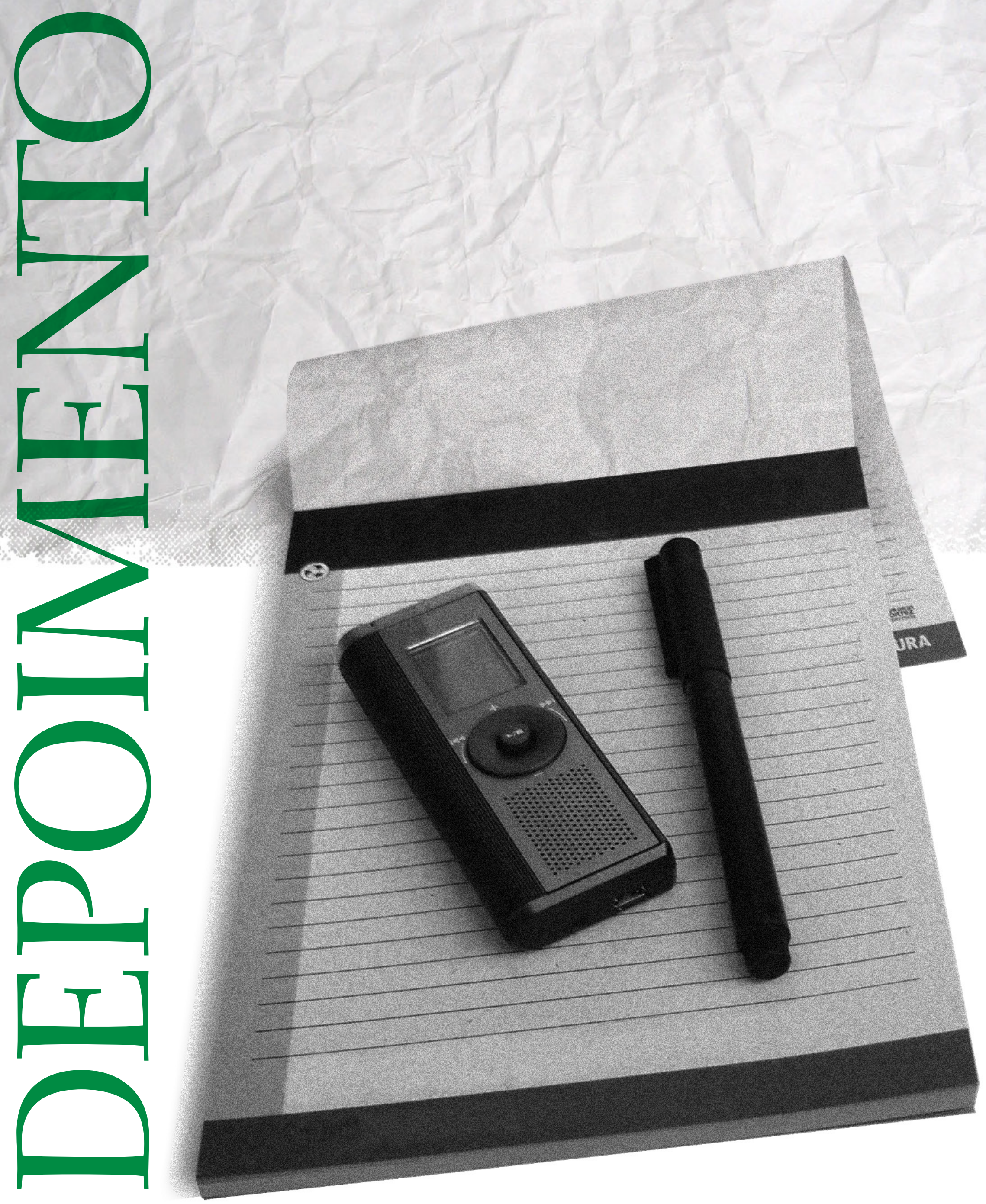


\section{2 lições aprendidas sobre comunicação da sustentabilidade em empresas: reflexões breves e propositadamente inconclusas}

12 lessons learned on communication of sustainability in corporations: reflections that are brief and purposely inconclusive

12 lecciones aprendidas sobre la comunicación de la sustentabilidad en empresas: reflexiones breves y propositalmente inconclusas

\section{Ricardo Voltolini}

- Jornalista e um dos primeiros consultores em sustentabilidade empresarial do Brasil

- Diretor-presidente de Ideia Sustentável: Estratégia e Inteligência em Sustentabilidade

- Escreveu Conversas com líderes sustentáveis (Senac-SP, 2011) e Escolas de líderes sustentáveis (Campus Elsevier, 2013, no prelo)

- Criou a Plataforma Liderança Sustentável, um movimento nacional que reúne 20 presidentes de empresas consagrados no tema da sustentabilidade

- É professor de sustentabilidade na Fundação Dom Cabral e na Universidade de São Paulo (FIA-USP, Poli-USP e ECA-USP)

- E.mail: ricardo@ideiasustentável.com.br 
niciamos este depoimento com uma constatação provocativa: a soma de consumidores mais informados, mídia mais vigilante, investidores engajados, leis mais restritivas e auto-regulação crescente representa um risco em potencial para empresas que querem utilizar a sustentabilidade em sua comunicação. Ao mesmo tempo, pode significar também uma enorme oportunidade.

A diferença entre um e outro extremo está no foco. Se a sustentabilidade for apenas um artifício de repaginação da imagem (sem correspondência efetiva com a visão de negócios), ao qual a empresa recorre pontualmente para obter o bônus da simpatia pública sem o ônus da mudança de práticas, então ela terá que se preocupar em "proteger" a marca contra a pressão de ONGs e de consumidores cada dia mais desconfiados nesses tempos de ascensão do que Daniel Goleman, autor de Inteligência ecológica, chama de transparência radical. Se, por outro lado, a empresa insere a sustentabilidade em sua estratégia e incorpora genuinamente os seus valores no modo de pensar e fazer negócios, ela certamente poderá adotá-la como elemento na construção de sua marca, usando a seu favor a crescente valorização do tema entre as pessoas de todo o mundo.

Em síntese, o que define, portanto, quanto de risco e de oportunidade há no uso da sustentabilidade para a comunicação da marca é a intensidade do compromisso e o nível de verdade nas práticas. Quanto mais claras e perceptíveis as incoerências, maiores os riscos. Quanto mais autêntica é a incorporação do tema na cultura da companhia, maiores as oportunidades. Simples assim.

Menos simples, no entanto, parece ser a tarefa de comunicar a sustentabilidade. Em todo o mundo, empresas e planejadores de comunicação enfrentam desafios que vão desde a escolha de conteúdos relevantes até as formas mais eficazes de transmitir as mensagens. Nesse terreno movediço, a experimentação tem sido a regra. Trabalhando com o tema nos últimos quinze anos, e com base em estudos e guidelines internacionais, reuni doze lições aprendidas que podem ser úteis para quem deseja comunicar melhor a sustentabilidade. Vamos a elas:

1) Identidade é tudo, imagem é pouco - Toda empresa precisa definir um posicionamento com o qual deseja ser percebida, junto aos seus diferentes públicos de interesse, em relação ao tema da sustentabilidade. O extinto Banco Real, um conhecido estudo de caso, consagrou-se como o banco da sustentabilidade. A Natura quer ser reconhecida como uma empresa preocupada com a biodiversidade. A Tetra Pak, como uma corporação atenta à reciclagem de embalagens. A IBM, como uma companhia dedicada a construir soluções para um planeta mais inteligente. E a Braskem, como a líder global da química sustentável. O posicionamento deve se basear em identidade clara, persuasiva, verdadeira. Precisa se expressar, de modo sintético, em ideias fortes e símbolos vivos. Uma empresa sustentável tem uma causa, um propósito que excede o do negócio, mas se expande nele e o legitima, inserindo-se na vida cotidiana das pessoas. 
O desafio de comunicar a sustentabilidade é, portanto, conferir verdade a essa causa e compartilhá-la com os públicos de interesse e a sociedade por meio de estratégias consistentes. A identidade define a linguagem e inspira. Constrói-se a partir de uma missão, uma visão e valores. Traduz o que a empresa faz para ser sustentável, como ela deseja ser no futuro e, principalmente, em que acredita. Como disse o filósofo francês Giles Lipovetski, "ética e estética andam abraçadas nesse mundo contemporâneo". Na comunicação da sustentabilidade, isso vale como regra de ouro.

2) Primeiro, o dever de casa - Antes de comunicar para fora, a empresa deve fazer a sua lição de casa, informar os funcionários e colaboradores sobre as políticas, ações e iniciativas. Precisa envolvê-los, fazendo-os se apropriarem da mudança e se sentirem "parte importante" dela, criar cultura para a sustentabilidade, alinhar conceitos e - por que não? - educar as pessoas.

Algumas empresas amargaram situações adversas por terem ignorado esse mandamento. Ficou notório o caso de uma grande empresa que, em 2009, surpreendeu a todos - inclusive os funcionários - com uma grande campanha de televisão, na qual apresentava seu posicionamento em sustentabilidade. O resultado não poderia ter sido mais frustrante: os clientes, desinformados, procuraram as unidades da empresa para entender melhor o que a propaganda propunha; os funcionários, igualmente desinformados, não souberam responder e - o que é pior -, céticos, desconfiaram até mesmo da verdade da ideia que estava sendo "vendida." Se uma empresa não consegue convencer os seus colaboradores de que é sustentável, muito provavelmente não o fará com os públicos externos. O que era para ser, portanto, um posicionamento, forte e marcante, virou pó algumas semanas e alguns milhões de reais depois.

Nesse sentido - vale destacar - a comunicação interna vem em primeiro lugar. Aqui, refiro-me a uma comunicação do tipo planejada, com posicionamento claro (missão e diferenciais), uma definição precisa de públicos (com quem se quer comunicar), objetivos bem delineados (que respostas se deseja obter), mensagens criativas (o que se deseja comunicar), estratégias eficazes (como e com que meios se pretende comunicar), monitoramento e avaliação de resultados. Nossa experiência mostra que, na pressa de "divulgar" ações, por não terem uma cultura baseada em valores ou uma política específica de onde retirar substrato para um posicionamento, as empresas queimam etapas importantes de planejamento, agindo quase sempre de modo pontual e espasmódico. Reflete notavelmente esse comportamento reativo o esforço de terceirização da "estratégia" de comunicação para fornecedores pouco afeitos ao tema.

3) Sustentabilidade são valores - A sustentabilidade se escora em um conjunto de novos valores que devem estar presentes na comunicação: diversidade, transparência, interdependência, respeito ao outro e ao ambiente. Tudo o que se opõe a isso tenderá a ser visto como velho e arcaico. Não tem verdade, não produz confiança. Boa comunicação é a que, de alguma forma, incorpora esses valores na mensagem. Mas, sobretudo, para ser efetivamente boa, 
a mensagem precisa refletir coerentemente as práticas da empresa, sob o risco de resultar em descrédito. Isso vale muito especialmente para a chamada comunicação institucional. Mas vale também para quando se usa a comunicação na venda de um produto como o plástico "verde", um carro elétrico, uma geladeira mais ecoeficiente.

4) Sustentabilidade é bacana - Houve um tempo em que sustentabilidade era tema restrito ao universo dos ambientalistas e objeto de uma defesa às vezes radical, outras vezes rabugenta. Hoje é preocupação global. Mas, como a sustentabilidade prega essencialmente a restrição (usar menos recursos naturais, andar menos de carro, consumir menos), ressaltando a escassez num mundo cujo modelo mental é o da abundância, corre-se o risco de que suas mensagens (até as mais bem intencionadas) soem demasiado engajadas. O limite entre o engajado e o chato é tênue no campo da comunicação. Daí ser recomendável algum cuidado para que a mensagem pró-sustentabilidade não propague regrinhas que alguém, em algum momento, por não entender sua relevância, deixará de cumprir. A sustentabilidade só vai se espalhar como ideia se for vista como algo atraente, divertido, charmoso e associado à noção de sucesso. Se as empresas quiserem emular mudanças de comportamento em nome de um novo tipo de desenvolvimento, deverão evitar profecias catastrofistas, palavras acusadoras, termos inquisitórios. As pessoas não devem se sentir "culpadas" por problemas como o das mudanças climáticas, mas corresponsáveis por sua solução. Humor ajuda. Otimismo é fundamental.

5) Ser confiável - Se desejarem produzir confiança em consumidores cada dia mais desconfiados, as empresas que utilizam o discurso da sustentabilidade terão de ancorá-lo em fatos e evidências comprováveis. Do contrário, darão tiros no próprio pé. Uma comunicação eficaz é exatamente aquela que consegue gerar confiança nos públicos, que abre janelas em sua percepção, toca algum sentimento positivo, respeita a sua inteligência, mobiliza emoções. Só a confiança constrói relações sólidas. E o que gera confiança num mundo de desconfiados em potencial? Fatos e não promessas, humildade e não arrogância, números e não suposições, políticas concretas e não projetos, práticas e não discursos, convicção e não conveniência, senso de oportunidade e não oportunismo.

6) Senso comum importa, sim - Antes de elaborar belos discursos, com palavras bonitas, os comunicadores precisam avaliar o quanto os seus públicos conhecem o tema e como falam sobre ele. Mais do que isso: como enxergam a empresa e os seus compromissos com o tema. Pesquisas de diferentes fontes indicam que algo próximo de três entre dez brasileiros consideram o desempenho de sustentabilidade de uma empresa na hora de comprar um produto. E que mais ou mesmo a metade dos consumidores desconfia de que o discurso de sustentabilidade seja um mero truque da empresa para lustrar sua imagem. Uma organização internacional, chamada Futerra, deu-se ao trabalho de pesquisar a eficácia da linguagem da comunicação da sustentabilidade. E acabou por elencar um conjunto de termos verdes (simpáticos e compreensíveis), amarelos (podem funcionar, mas ainda não se mostraram efetivos) e vermelhos (desagradáveis e facilmente mal interpretados). Não seria má ideia fazer o mesmo por aqui. 
7) Menos adjetivo, mais substantivo - Inserir o adjetivo "sustentável", como algo absoluto, informa e mobiliza ou desinforma e aumenta a desconfiança? As expressões "verde", "natural" ou "orgânico", por si sós, e sem complementos, ajudam a vender um produto? Você preferiria um produto que tem na embalagem um selo "mais verde" não verificado por uma organização terceira idônea? Publicar num press release que a empresa fez doação de produtos para uma comunidade pobre revela uma posição madura em relação ao conceito de sustentabilidade? Interessa como notícia? A quem? Quanto o consumidor de uma empresa acreditará na mensagem de que ela "tem compromissos ambientais sólidos" se segue lançando resíduos líquidos poluentes no rio que abastece a sua comunidade? Quão eficiente será a mensagem sobre "apoio à melhoria da mobilidade urbana" difundida por uma montadora que despeja volumes industriais de automóveis nas ruas dos grandes centros urbanos? Comunicação, já se sabe, não é o que se diz, mas o que se entende. Compreensão é mais importante do que qualquer rigorismo técnico.

8) “Nós" e "você" - A sustentabilidade do planeta não é problema do outro, mas de todos nós. Boas mensagens são, portanto, as que adotam um tom inclusivo, próximo, leve, pessoal e humano. São as que nos tornam cúmplices do mesmo processo de mudança. Deve-se substituir, portanto, o tom distante do "Eu faço, eu sou..." por um mais inclusivo do tipo "Nós procuramos fazer, nós tentamos melhorar...". Afinal, a única verdade que se tem como absoluta em sustentabilidade é que estamos todos no mesmo barco. O tema precisa servir para aproximar as pessoas em torno de uma causa comum e não afastá-las. Convém eliminar também o autoelogio, o tom relatorial, frio e hierárquico; a linguagem áspera, seca e impessoal. Recomendase um tom mais próximo, sincero e baseado em narrativas que façam sentido para a vida das pessoas. Não se está falando de algo "empresarial", fora do universo humano. Mas do próprio humano que há no empresarial.

9) Contar histórias - Histórias geram empatia e despertam emoções poderosas. Em um mundo bombardeado por narrativas de toda espécie, as que tratam da sustentabilidade podem ter também o seu lugar de destaque se forem bem contadas. Devem estar na boca de líderes de empresas, governos e organizações da sociedade civil. Líderes apaixonados.

Tomemos como exemplo os relatórios de sustentabilidade. O número de empresas que passaram a publicá-los, sob o formato Global Reporting Initiative (GRI), o mais consagrado em todo o mundo, cresceu exponencialmente nos últimos cinco anos. A qualidade, no entanto, não acompanhou o crescimento quantitativo. Embora bem urdidos do ponto de vista técnico, estruturados com base em indicadores abrangentes e oportunos, eles são quase sempre peças de comunicação extensas, áridas, enfadonhas e de leitores escassos que interessam - quando muito - à consulta pontual de um ou outro stakeholder da empresa. Sobram números, gráficos e indicadores. Faltam histórias.

10) Heróis são importantes - Em escala mundial, a sustentabilidade ainda não fabricou grandes heróis. Ter em quem se inspirar ou a quem seguir, por convicção e crença, 
ajuda na comunicação da sustentabilidade. Heróis são mitos. E mitos, como se sabe, estão impregnados na experiência humana. Empresas, comunidades, estados e países devem forjar os seus heróis da sustentabilidade.

11) Grande quadro - A sustentabilidade é um dos mais importantes compromissos humanos deste início de século. Tem a ver com cada indivíduo e também com o coletivo de todos os indivíduos do planeta. Trata-se de uma grande revisão mundial de valores, práticas e comportamentos. Por isso, qualquer ação de comunicação deve explorar essas conexões, apresentar pensamentos no longo prazo e mostrar que o futuro começa agora. No campo do simbólico, deve transmitir otimismo, fé na vida, altruísmo, respeito ético pelo ambiente e pelas pessoas. Valorizar o que é diverso. Vender o sentimento de que não se sabe tudo, mas se quer aprender. Não intimar a participar, mas convocar vontades. Mostrar gente com cara de gente, meio ambiente próximo. Dar aos receptores das mensagens a possibilidade de reconstruí-las simbolicamente, de se apropriar delas, de se identificar com o que é comunicado.

12) Não comunicar não significa que se está livre de comunicar - Há empresas que escolhem não adotar os temas de sustentabilidade como mote de sua comunicação, por razões que incluem desde o sentimento de que acrescentam pouco valor tangível à marca até o receio de praticar o chamado greenwashing. Comunicar para o grande público, comunicar em círculo restrito ou não comunicar sustentabilidade são decisões que dependem do tipo de negócio, dos impactos socioambientais provocados por ele, do nível de pressão social sofrido pela empresa e, claro, de sua cultura. Nem mesmo as empresas low profile - vale dizer -- estão livres de ter de comunicar o tema. A Zara é um bom exemplo disso. Em 2011, a empresa foi denunciada pelo Ministério do Trabalho de São Paulo por contratar costureiros bolivianos em condições degradantes. $O$ fato transformou-se em escândalo, virou polêmica nas redes sociais, desgastou a imagem e trouxe prejuízos de reputação à empresa espanhola, obrigando-a a se posicionar publicamente para se salvaguardar. Até a ocorrência, a Zara não tinha sequer uma estrutura de comunicação no Brasil. Ter uma estrutura de comunicação foi providencial para que a BP inglesa sobrevivesse, em 2010, ao triste episódio do vazamento de petróleo no Golfo do México. Raras vezes uma empresa foi tão duramente castigada por um descuido de segurança operacional. Os temas de sustentabilidade representarão um percentual importante dos motivos de crise de imagem de empresas nos próximos anos. 